\title{
Hematopoietic stem cell transplantation: clinical use and perspectives
}

\author{
Francisco Barriga ${ }^{1}$, Pablo Ramírez, Angélica Wietstruck, Nicolás Rojas \\ Department of Pediatrics and Hematology Oncology, Pontifical Catholic University of Chile, Santiago, Chile.
}

\begin{abstract}
Hematopoietic stem cell transplantation is the accepted therapy of choice for a variety of malignant and non-malignant diseases in children and adults. Initially developed as rescue therapy for a patient with cancer after high doses of chemotherapy and radiation as well as the correction of severe deficiencies in the hematopoietic system, it has evolved into an adoptive immune therapy for malignancies and autoimmune disorders. The procedure has helped to obtain key information about the bone marrow environment, the biology of hematopoietic stem cells and histocompatibility. The development of this new discipline has allowed numerous groups working around the world to cure patients of diseases previously considered lethal. Together with the ever growing list of volunteer donors and umbilical cord blood banks, this has resulted in life saving therapy for thousands of patients yearly. We present an overview of the procedure from its cradle to the most novel applications, as well as the results of the HSC transplant program developed at our institution since 1989.
\end{abstract}

Key words: hematopoietic, stem cells, transplantation, allogeneic

\section{INTRODUCTION}

Hematopoietic stem cell transplantation (HSCT) remains until now the only proven clinical use of stem cells. Since the discovery of this procedure in the early 1960s as a cure for hematologic cancer and both congenital and acquired diseases of the hematopoietic system (Fig. 1) (Pasquini \& Wang, 2011; Thomas et al., 1975), significant progress has been made to make HSCTs safe and available to all patients with a clinical indication of the procedure.

\section{HEMATOPOIETIC STEM CELLS (HSC) AND THE NICHE}

HSC sustain blood cell production over the entire life of an individual. Initially during embryonic life HSCs develop in different anatomical places, beginning in the mesodermal germ layer which gives rise to the hemangioblasts (Huber et al., 2004). Subsequently a second short wave of erythroid progenitors originates from the yolk sac and later the liver becomes the third structure that gives rise to definitive erythroid differentiation (Gekas et al., 2005). HSCs that originate complete hematopoiesis are found initially in the aorta-gonad-mesonephros (AGM) region for a short period in a low number of cells. Subsequently the main place of HSC accumulation coming from the yolk sac and the AGM region corresponds to the fetal liver (Ema \& Nakauchi, 2000). Finally, the hematopoiesis transfers to the bone marrow where it will contribute to the definitive adult hematopoietic system through the entire life of the individual.

The first demonstration of the existence of HSCs was reported in 1961 by Till and McCulloch (1961). Later the concept of the hematopoietic stem cell niche emerged, a highly specialized place where stem cells localized in the bone marrow (Schofield, 1978).

Currently the adult HSC niche is known to involve several other cell types that support HSCs including osteoblasts, osteoclasts, mesenchymal stem cells, adipocytes and neuronal cells, among others (Doan \& Chute, 2012). Also, a network of extracellular matrix proteins and surface molecules are pivotal for HSC survival, self-renewal, proliferation, differentiation and trafficking (Rettig et al., 2012).

At least 2 different niches have been described within the niche concept; the osteoblastic niche and the vascular niche, with different localizations and functions (Till \& McCulloch, 1961). The former corresponds to the area where HSCs are in direct contact with the endosteal surface and the osteoblasts; evidence has shown that stem cell fate is regulated by the direct contact between HSCs and osteoblasts through Notch activation (Calvi et al., 2003; Yin \& Li 2006). The vascular niche in the adult individual has been shown to be an area of HSC regulation. It has been demonstrated that in vitro, endothelial cells are able to expand significantly HSCs, probably through via soluble factors (Chute et al., 2002; Zhang et al., 2008). In vivo several studies have supported the existence of an anatomical vascular niche (Kiel et al., 2005; Lo Celso et al., 2009; Kopp et al., 2005).

The HSC-niche interactions subsequently induce the production of more differentiated precursors and finally mature blood cells which will be the components of the hematological and immune systems.

\section{CLINICAL HSC TRANSPLANTATION}

HSC transplantation (HSCT) is a procedure in which the entire hematopoieses and immune system are replaced by the donor's cells (Copelan, 2006). HSCT can be classified according to its purpose, HSC origin and HSC donor type (Tables 1, 2 and 3). Matching in allogeneic transplantation is done by comparing alleles of the human histocompatibility locus (HLA) located in chromosome 6. HLA antigens are classified in class I (A, B, C) and class II (DRB1, DQB1, DPB1), and matching between donor and patient can be done at low, intermediate and high resolution (Petersdorf, 2008). Indications for HSC 
transplantation are malignant and non-malignant diseases (Fig. 1). Most HSCT procedures are performed with autologous HSC for different forms of cancer, with multiple myeloma being the most common indication. Nevertheless, the development of equally effective and less toxic procedures is resulting in a decreasing use of this procedure as therapy for these patients. Most allogeneic transplants are performed for patients with hematologic malignancies, mainly acute leukemias. Chronic myelogenous leukemia was the most common indication until tyrosine kinase-based therapy became available and proved to

TABLE 1

Purpose of HSCT

1. Rescue a patient with cancer from the toxic effects of high dose chemotherapy $+/$ - radiation therapy (autologous or allogeneic)

2. Correct a congenital or acquired severe blood disorder by replacing the patient's with the donor's hematopoietic system (allogeneic)

3. Increase the control of a malignant disease by alloimmune effector mechanisms of the graft versus host reaction (allogeneic)

4. Reset the immune system to abolish autoimmunity (autologous or allogeneic)

TABLE 2

\section{Donor sources in HSCT}

1. Bone marrow, harvested by multiple punctures and aspiration of posterior iliac crests

2. Mobilized peripheral stem cells, obtained by leucopheresis after administration of granulocyte stimulating factor

3. Placental blood collected through the umbilical cord at the time of delivery

TABLE 3

\section{Donor types in HSCT}

1. Autologous: HSC are obtained from the patient

2. Allogenic: HSCs are obtained form a donor
a. Matched related, sibling.
b. Mismatched related: partially matched family member. This graft usually requires graft manipulation either negative $\mathrm{T}$ cell selection or positive CD34 selection (haploidentical)
c. Matched unrelated: HSC from an unrelated donor that satisfies match criteria similar to a sibling donor
d. Mismatch unrelated: HSC from an unrelated donor with major o minor mismatches in HLA type

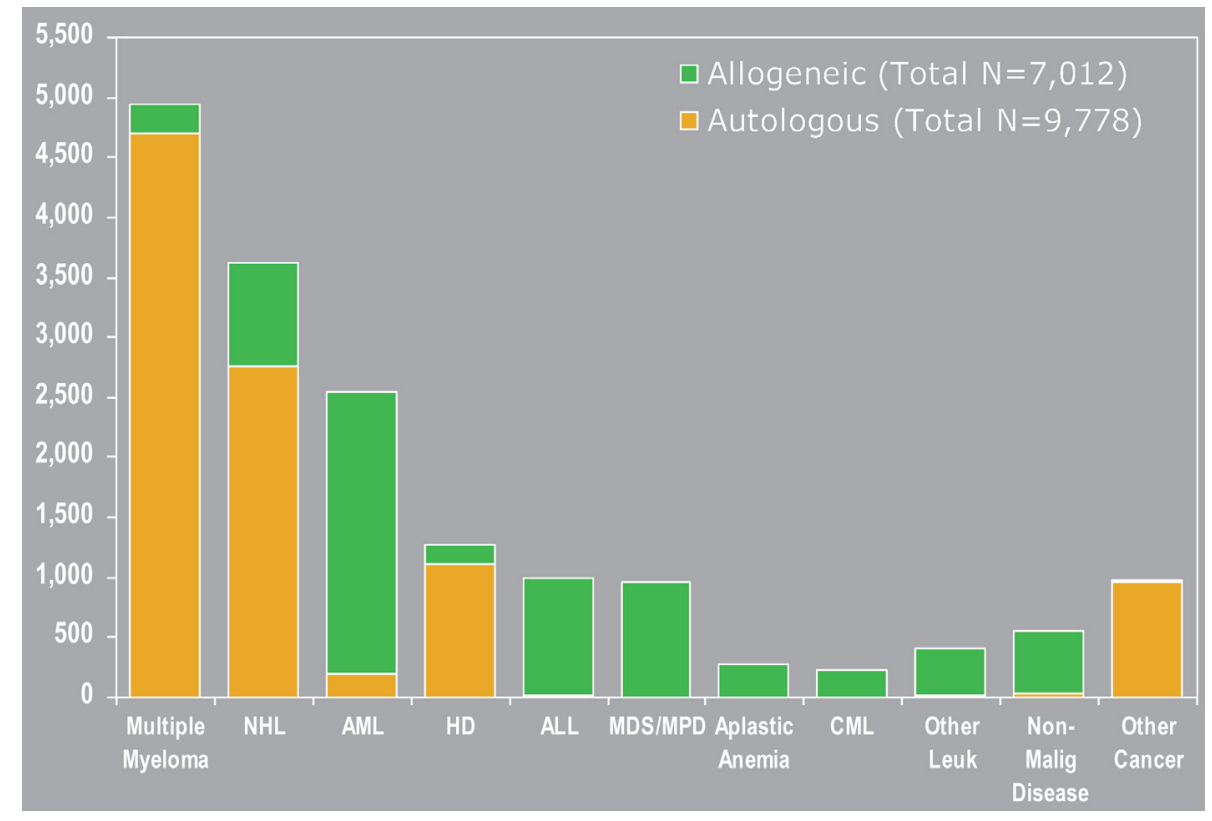

NHL: Non Hodgkin's lymphoma, HD: Hodgkin's disease, AML: acute lymphoblastic leukemia ALL: acute lymphoblastic leukemia, MDS/MPD: Myelodisplastic syndromes, CML: chronic myelogenous leukemia.

Figure 1. Indications for Hematopoietic Stem Cell Transplants in the United States, 2009. Center for International Bone Marrow transplant Research (www.cibmtr.org). 
be a better alternative, particularly in older patients in the early phases of the disease. Transplantation in this group is now reserved for younger patients and when leukemia becomes resistant to tyrosine kinase inhibitors.

To engraft allogeneic HSCs successfully, a patient has to receive some form of immune ablative therapy or conditioning regimen before transplantation. In patients with hematological malignancies this is usually accomplished by the use of chemotherapy and total body radiation, which also function as anticancer therapy. Conditioning regimens are termed myeloablative when high doses of both radiation and chemotherapy are used and reduced intensity when lower doses are used. The intensity of the conditioning regimen depends on the underlyimg diagnosis, age of the patients and co-morbidities. Reduced intensity regimens have allowed extension of the procedure to older and sicker patients (Kassim et al., 2005).

The most limiting complication for allogeneic HSCT is graft versus host disease (GVHD), an immune rejection to host tissues mediated by donor lymphocytes which results in a skin rash, diarrhea and liver disease (Ferrara et al., 2009). This condition can become chronic and produce a systemic sclerosis-like illness which can produce scarring of the skin, gut and eyes (Horowitz \& Sullivan, 2006). The most important factor that determines the incidence and severity of GVHD is HLA matching.

Transplantation failure is due to either disease relapse in patients transplanted for malignancies or to mortality related to the procedure, almost always due to infections and sometimes as a result of conditioning-induced organ damage. Infections by common and opportunistic microorganisms is a consequence of the profound immune suppression of patients and the prolonged recovery of innate and adaptive immunity (Table 4). GVHD is a contributing factor to infectious complications because of the further delay in immune reconstitution it provokes.

\section{HISTORICAL EVOLUTION: HOW HURDLES WERE OVERCOME}

Bone marrow transplantation was performed successfully as a result of the studies done by Donnall Thomas and the group at the Fred Hutchinson Cancer Center during the 1960s. Early studies demonstrated the effect of high radiation therapy doses and chemotherapy in the bone marrow as well as the capacity to regenerate the individual's hematopoietic function by reinfusion of stored bone marrow cells from the individual or a donor (Lorenz et al., 1951; Mannick et al., 1960; Santos \& Owens 1969).

To control GVHD two issues had to be dealt with: histocompatibility and post-transplant immune suppression. The first was accomplished with the continuous improvement of HLA matching from antigen to allelic typing, as well as the discovery of an ever growing list of class I and II alleles. The second was successfully dealt with by the introduction of calcineurin inhibitors, mainly cyclosporine, a potent immune suppressor developed for solid organ transplantation (Choi et al., 2010).

Infection control has improved significantly with the introduction of wide spectrum antibiotics, effective antifungals and an ever growing list of antivirals developed to curb the activation of latent or acquired disease. The use of controlled hospital environments to control the spread of airborne fungi goes in this direction (Tomblyn et al, 2009).

The second source of HSCs to enter the clinic were peripheral SC obtained form a healthy donor after mobilization with granulocyte stimulating factor and collected via leukapheresis. This avoids a painful surgical, and results in faster engraftment of granulocytes and platelets as well as improved immune reconstitution compared to bone marrow grafts (Storek et al, 2001).

The recognition of umbilical cord blood as a source of HSCs that can repopulate the marrow of a patient was reported in 1988 in a Fanconi anemia patient (Gluckman, 2009), based on previous work by Broxmeyer (2009) and Knudtzon (1974). The successful results of transplantation in children using cord blood grafts stimulated its use in adult patients. The main limitation was and remains the low cell number, with slow hematologic and immune reconstitution and initially high transplant-related mortality (Gluckman et al., 1997; Rubinstein et al., 1998). Several strategies are under evaluation to improve the results of umbilical cord blood transplantation (UCBT) in

\section{TABLE 4}

Prevalence of opportunistic infections after allogenic HSCT in the different post transplantation periods.

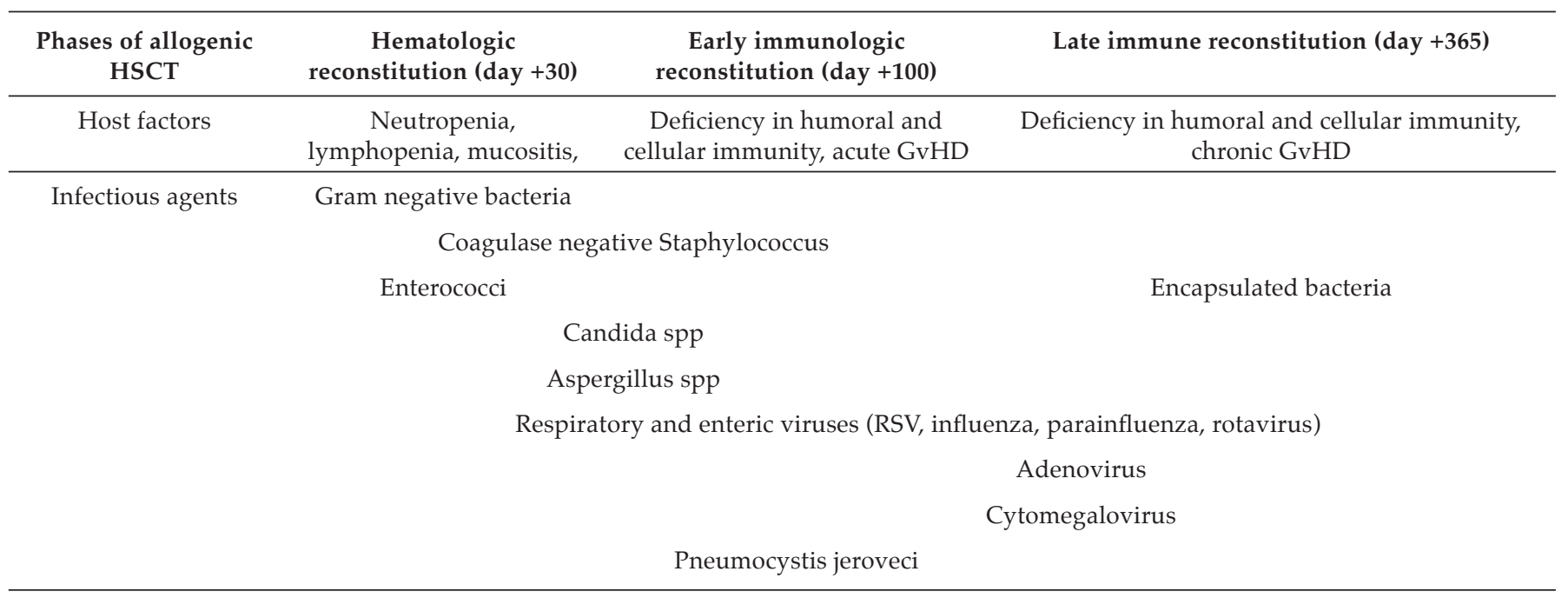


adults and large children. The most successful corresponds to double UCBT. Considering that most of the adult patients do not qualify for UCBT due to their weight and their minimum nucleated cell requirements, this is achieved with 2 UCB units. Several groups have published their results (Barker et al., 2003; Gutman et al., 2009; Brunstein et al., 2010). Overall, these studies have shown that myeloablative conditioning followed by double UCB graft infusion is associated with acceptable engraftment rate and long term overall survival, similar to adult graft sources. Interestingly, these studies have demonstrated the predominance of one of the 2 units shortly after transplant. The mechanisms are not fully understood but most likely are immunological in nature (Gutman et al., 2010; Ramírez et al., 2012). Large retrospective studies in Europe and the US comparing results between unrelated cord blood and adult volunteer donors have shown similar overall survival (Rocha et al., 2004; Laughlin et al., 2004). Important differences between the HSC sources are depicted in Table 5.

\section{UNRELATED DONOR TRANSPLANTATION}

Once transplantation from fully matched siblings and well matched relatives was done safely, the problem of patients without such a donor became the first priority. To this effect volunteer donor registries were started first in Europe (Anthony Nolan, UK, 1974) and later in the US (National Donor Marrow Program, 1986). These registries were quick to collaborate and large databases of donors from many registries were united (Bone Marrow Donors Worldwide). These efforts have resulted in more than 20 million donors recruited to date in all continents, providing thousands of HSC products for transplantation (WMDA) (Foeken et al., 2010). Despite this effort only $50 \%$ of the patients searching for an unrelated donor find one, and this average is widely variable among different ethnic backgrounds. The finding that umbilical cord blood was an alternative source of HSCs spurred the creation of public access cord blood banks which have meant a

TABLE 5

Comparison of the main features of UCBT and BMT (adapted from SCHOEMANS et al.)

\begin{tabular}{lcc}
\hline & UCB & BM/PBSC \\
\hline Number of available donors as 07 07/2012 & 563,6926 units & $19,585,600$ donors \\
Major limiting factor & Fixed unit cell content & HLA match and donor attrition \\
Minimum number of total nucleated cells for transplant & Aprox 2,5x107/kg & Aprox $2.0 \times 108 / \mathrm{kg}$ \\
Second graft or DLI & Impossible & Possible \\
Median speed of donor availability & 1 day & $3-4$ months \\
Donor morbidity & None & Fatigue, local pain, lower back pain \\
EBV / CMV transmission to recipient & Negligible & Possible \\
Risk for transmission of congenital diseases & Theoretically possible & None \\
Standard HLA match requirements & Minimum $4 / 6$ & Mostly $8 / 8$ \\
\hline
\end{tabular}

UCB: umbilical cord blood; BM/PBSC: bone marrow/peripheral blood stem cells; DLI: donor lymphocyte infusion; EBV/CMV: Epstein Barr virus/Cytomegalovirus

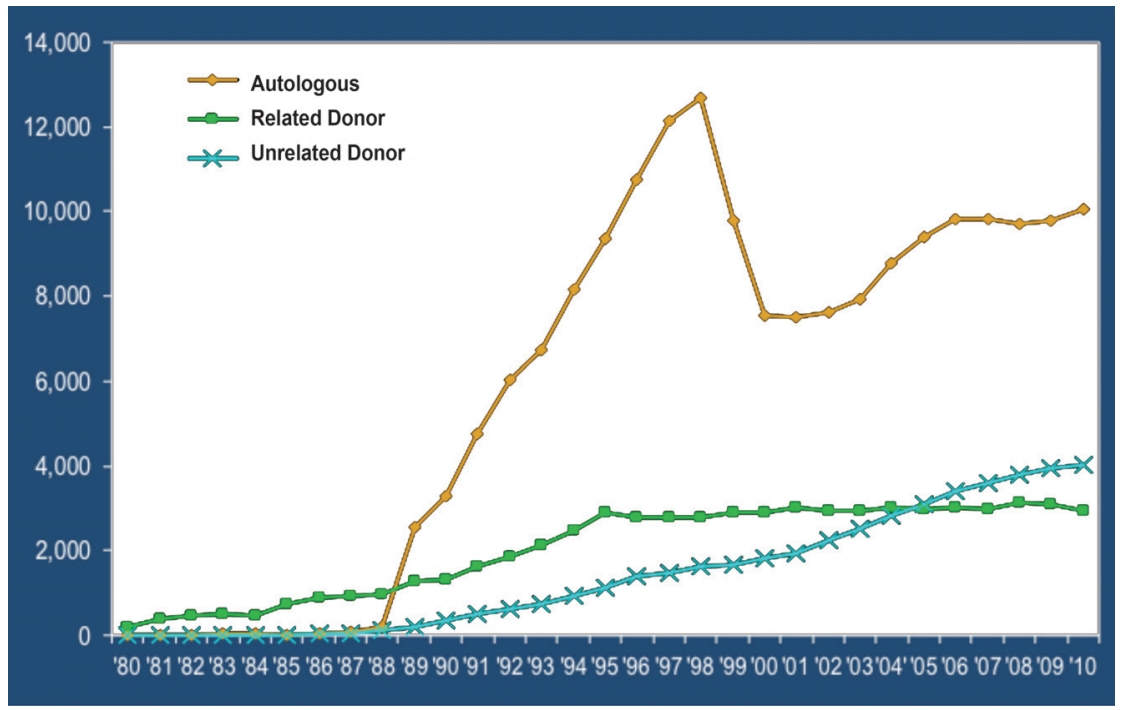

Figure 2. Transplant activity in the US 1980-2010. Center for International Bone Marrow transplant Research (www.cibmtr.org) 
significant increase of the unrelated donor pool, especially for the pediatric age population. By 2012 an estimated 500,000 cord blood units have been stored globally (Bone Marrow Donors Worldwide). These banks obtain cord blood from donations; the blood is collected on delivery and white blood cells are purified, mixed with DMSO and frozen in liquid nitrogen. The units are then characterized (HLA, infectious diseases) and offered for clinical use through the multiple donor registries.

\section{DONOR AVAILABILITY FOR UNRELATED DONOR TRANS- PLANTATION}

As more transplant teams are established and more donors are available worldwide, the number of allogeneic procedures has increased by nearly $30 \%$ in the past decade both in the US (Fig. 2) (Pasquini \& Wang, 2011) and in Europe (Fig. 3) (Passweg et al., 2012). Mobilized peripheral stem cells have become the fastest growing stem cell source in adult transplantation and umbilical cord blood in children (Foeken et al., 2010) (Fig. 4). The growth of adult volunteer donor registries and the establishment of large cord blood banks have increased the available donor pool for unrelated transplantation. The present number of registered donors in Bone Marrow Donors Worldwide exceeds 20,000,000, including over 500,000 stored umbilical cord blood units which represent a nearly 12 -fold increase in 20 years (Figure 5). Despite all this progress, transplant activity differs widely between developed and developing countries. The World Marrow Donor Association

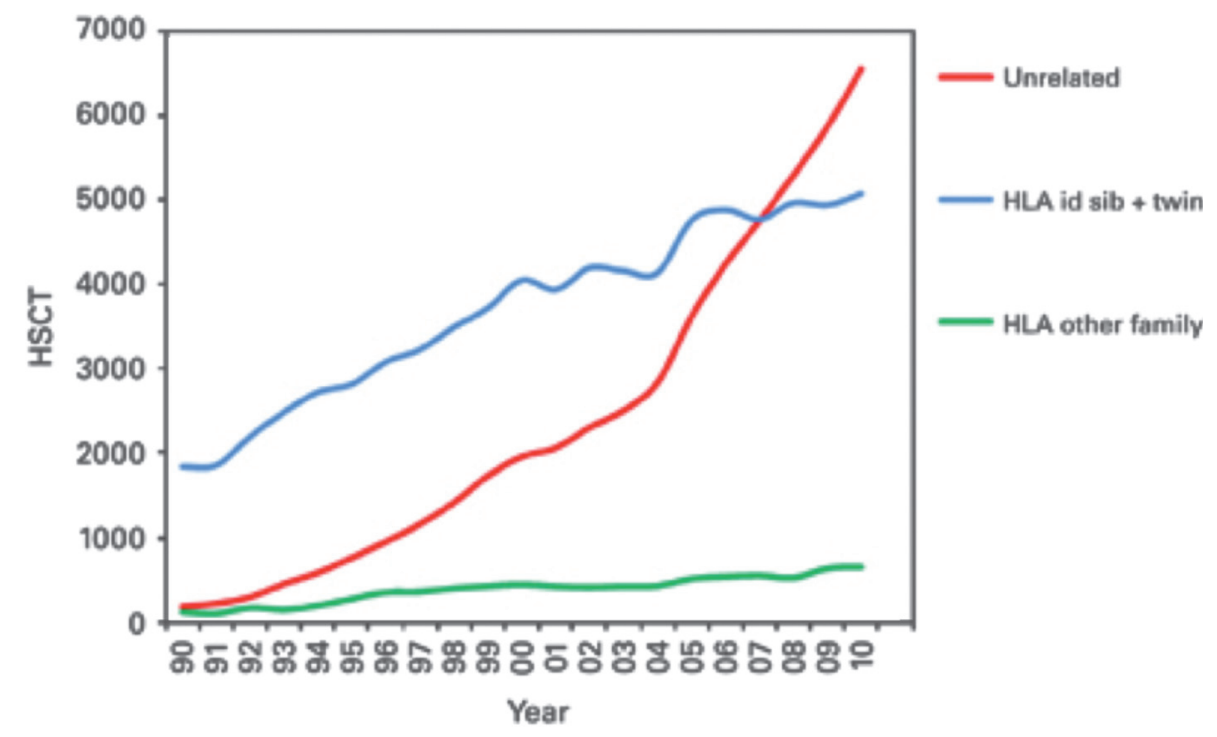

Figure 3. Allogenic Transplant activity in Europe (EBMT) 1990 to 2010 (Passweg et al., 2012).

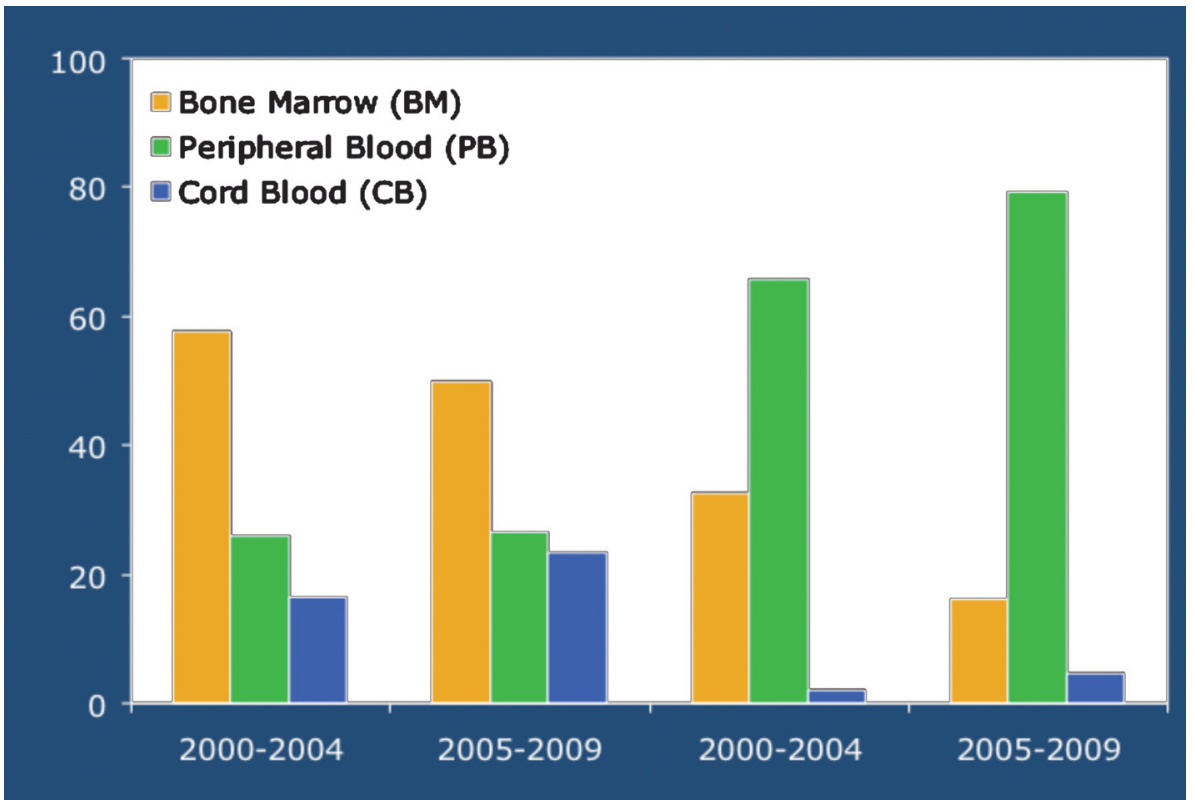

Figure 4. Allogeneic Stem Cell Sources by Recipient Age 2000-2009 (Pasquini ans Wang et al., 2011). 
reported in 2010 the rate of unrelated donor transplants. Procedures per 10 million habitants in developed countries ranged from 82 (Spain) to 224 (Germany) while the reported activity in South America in that same period was 6 to 14 transplants per 10 million. This reflects the high level of medical infrastructure and human resources needed to implement this procedure successfully.

The use of T lymphocyte-depleted HSC grafts from haploidentical family donors has also gained acceptance in many groups trying to overcome donor shortage. This procedure is directed towards eliminating $\mathrm{T}$ alloreactive cells in the graft and avoiding GVHD; many centers have improved its efficacy and safety, resulting in a slow gain of acceptance.

\section{ALLOGENIC TRANSPLANTATION FOR HEMATOLOGICAL MALIGNANCIES}

Acute and chronic leukemia constitute the most common indications for allogeneic HSCT. The mechanisms by which HSCT can cure leukemia are twofold: the high doses of chemotherapy and radiation the patients receives before infusion of the HSC graft (conditioning or preparatory regimen); and the immune-mediated graft versus leukemia reaction which mirrors GvHD. The relative importance of each is not well defined, and as the graft versus leukemia GVL reaction is better understood, more patients are being prepared with less intense doses of chemotherapy and radiation, favoring engraftment but reducing toxicity and transplant-related mortality.

Long term results in malignant diseases have classically depended on patient age, donor source (matched versus mismatched, related versus unrelated) and stage of disease. Patients in early clinical remission fare much better than patients who have experienced multiple relapses or are no longer responsive to chemotherapy. Because of this many centers will omit transplanting a patient with active disease outside a clinical trial.

\section{ALLOGENIC TRANSPLANTATION FOR NON-MALIGNANT DI- SEASES: EXPANDING INDICATIONS}

Allogeneic HSCT not only plays an important role in the treatment of children and adolescents with malignant diseases but it is also an effective therapy for a wide range of nonmalignant diseases including hemoglobinopathies (thalassemia, sickle cell disease), congenital or acquired bone marrow failure syndromes, primary immunodeficiencies and inherited metabolic disorders. In each of these diseases, donor-derived cells have the ability to correct the underlying defect, either by direct repopulation of the hematopoietic and immune systems or by indirect delivery of the missing enzymes or other critical building blocks across the cell membranes. Contrary to what is emerging in HSC transplants for malignant diseases, the best results are still obtained with the use of identical sibling donors, which only applies to $20 \%$ of these patients. Thus the number of transplants using unrelated donors (cord blood and adult peripheral blood or bone marrow) has increased in recent years, with variable results that depend on the donor, number of cells, degree of mismatches, co-morbidity of the patient and time of transplantation. The European Group for Blood and Marrow Transplantation published the recommendation for the use of HSCT in non-malignant diseases; in some entities the transplant is considered the standard of care and in other cases this option of treatment must be considered in relation to the condition of the patient and the decision of the team and the family (Ljungman et al., 2010).

Primary immunodeficiencies are inherited disorders characterized by impairment of innate or adoptive immunity, commonly leading to lethal complications. Allogeneic HSCT can cure most of the lethal forms of immunodeficiencies, including severe combined immunodeficiency (SCID), several T-cell immunodeficiencies, Wiskott-Aldrich syndrome, phagocyte disorders such as leukocyte adhesion deficiency and chronic granulomatous diseases, haemophagocytic syndromes such as familial lymphohistiocytosis, Chediak-Higashi

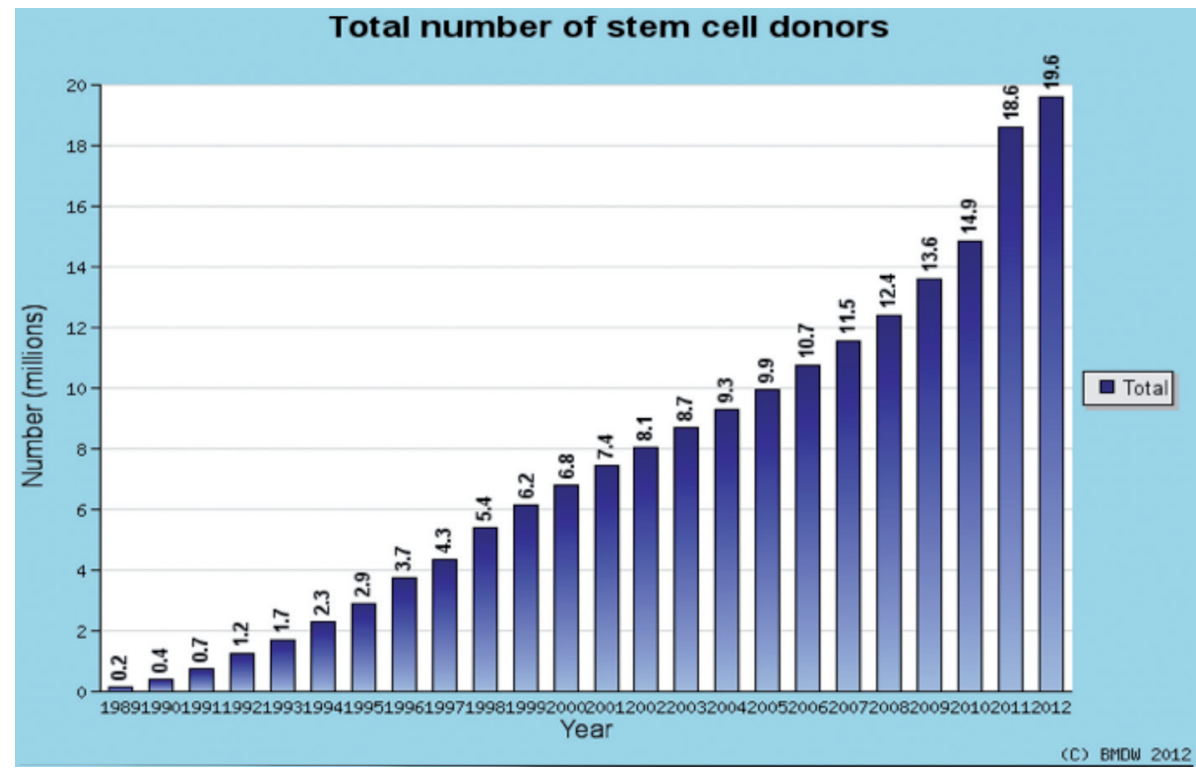

Figure 5: Unrelated stem cell donors registered with Bone Marrow Donors Worldwide 1989 to 2012 (www.bmdw.org). 
syndrome, Griscelli's disease and X-linked lymphoproliferative syndrome. Treatment by HSCT is increasingly successful and is indicated from both HLA-identical and alternative donors. Patients with severe congenital immunodeficiencies need to be grafted as soon as possible. An allogeneic HSCT results in a survival rate of more than $90 \%$ when carried out shortly after birth. Prognostic factors are age, type of SCID, clinical state at the time of diagnosis, in particular the presence of a lung infection and degree of HLA histocompatibility (Wachowiak et al., 2008; Slatter \& Cant, 2012). Allogeneic HSCT with an HLAidentical family donor is the treatment of choice for children with acquired severe aplastic anemia (Muñoz Villa et al., 2008). The use of alternative donors is restricted to patients who have failed other forms of therapy, and in these patients transplantrelated mortality remains a significant problem mainly due to late or non engraftment (Maury et al., 2007). Children with Blackfan-Diamond anemia having a matched sibling should be transplanted if they do not respond to steroids or if they become dependent on them (Vlachos \& Muir, 2010). Children with Fanconi anemia should be transplanted when they develop severe hematological disease if they have an HLAidentical sibling donor or a well-matched unrelated donor.

Allogeneic HSCT is the only currently available clinical treatment for many inherited metabolic diseases that lack effective enzyme replacement therapy, such as lysosomal and peroxisomal storage disorders (adrenoleukodystrophy, certain mucopolysacharidoses and sphyngolipidoses). Allogeneic HSC can correct these disorders in part by differentiation into monocyte macrophage cells such as microglia in the brain, Kupffer cells in the liver and alveolar macrophages in the lungs. These can induce long-term metabolic correction and ameliorate neurocognitive and functional problems (Krivit, 2004). Moreover, donor-derived cells induce 'cross-correction', a phenomenon by which the close proximity of normal cells can correct the biochemical consequences of enzymatic deficiency within the neighboring cells. Evidence of extensive distribution of donor cells in the blood vessels, peri-ventricular tissues, cerebral white matter, cerebellum, choroid plexus and forebrain parenchyma have been described (Krivit, 2004). Recent reports of large series have underlined the importance of transplantation in the early stages of the disease before significant organ and tissue damage occur (Prasad et al., 2008).

Hemoglobinopathies, such as thalassemia, sickle cell disease (SCD) and other complex defects, can cause major morbidity, poor quality of life and early death from the combined effects of anemia, hemolysis, iron overload and ineffective erythropoiesis. Early transplantation from a suitable donor prevents and reverses many of these problems. Because of different natural histories, the specific questions regarding the time of transplantation, criteria for patient selection and supportive care guidelines differ for patients with thalassemia and SCD. However, limitations of donor availability and risks of potentially serious toxicities have prevented HSCT from becoming the standard of care. To help define the patient selection criteria in thalassemia and an individual patient's risks from transplantation, Lucarelli et al. developed a scoring system on the basis of chelation therapy (regular or irregular), hepatomegaly and liver fibrosis, which predicted the risks of transplantation in patients with beta thalassemia (Lucarelli et al., 1993). This score has helped in the selection of both patients and donors for transplantation. Developments of conventional therapy have improved both the quality and the duration of life for patients with sickle cell disease (SCD). For this reason, HSCT from an HLA-identical sibling is offered only to a subset of patients at high, life-threatening risk or to patients who cannot receive adequate support (Shenoy, 2011).

\section{THE HSC TRANSPLANT PROGRAM AT THE PONTIFICAL CATHOLIC UNIVERSITY OF CHILE}

Our institution commenced this program in late 1989 and its evolution has paralleled the challenges and advances in the field. 475 transplant procedures have been performed in children and adults since its inception. Initially, autologous and matched sibling transplants were performed in standard risk patients with malignant and non-malignant diseases. Allogeneic transplantation quickly became the center of our effort as indications widened during the 90's. Having safely established the sibling donor program we began to perform unrelated cord blood transplants in 1996, shortly after the first reports of its use were published (Rubinstein, 1998). During that period adult volunteer registries were restricted to centers outside the US and Europe, making this donor source unavailable. Unrelated cord blood, despite being the last source to be developed, bridged the gap that allowed us to solve the problem of patients lacking a family donor. Ten years later we started to procure grafts from adult donor registries after the National Marrow Donor Program launched an initiative to widen the use of unrelated transplantation worldwide. Nowadays our search process is initiated through Bone Marrow Donors Worldwide and registries with potential donors are contacted after the initial search. From 1989 through 2011, 268 patients have received an allogeneic transplant. Figure 6 depicts our program's allogeneic transplant activity in 4 -year periods since 1989, showing that in the last period the number of unrelated donor transplants surpassed those of siblings, in accordance with the global tendency.

Indications for allogeneic transplants in our program have mirrored those reported by CIBMTR (Table 6). Most patients are transplanted for hematological malignancies, mainly acute leukemia (68\%), and most of them have received myeloablative conditioning including total body irradiation. 150 patients $(71 \%)$ transplanted for malignancy had early disease (acute leukemia in first or second complete remission, chronic myelogenous leukemia in chronic phase, untreated myelodysplasia). 58 patients have been transplanted for nonmalignant disorders, 45 of them children $(77 \%)$ and $26(40 \%)$ with the diagnosis of severe aplastic anemia have been almost all children. 170 patients received a graft from a sibling or well matched relative $(63 \%)$, and 98 from an unrelated donor $(86 \%$ cord blood).

5-year overall survival for patients with malignancies was $48 \%$. We analyzed risk factors for overall survival during the period 1997-2007, when the unrelated donor program started. The only predictive factor for survival was disease stage (early $58 \%$, advanced $12 \%$, p $<0.001$, Fig. 7). For patients with early disease no differences were seen comparing patient age ( $<18$ years, $43 \%$; 18 or more $51 \%$ ), donor source (related $62 \%$; unrelated 59\%), nor study period (1997 to 2005, 57\%; 2006 to $201163 \%$ ).

5-year overall survival for patients with non-malignant disorders in the pediatric age group was $62 \%$. Due to the wide diversity of diseases in this group we sought to identify prognostic factors that could apply to all of them. Three such 
TABLE 6

Patient and donor characteristics of the HSCT program at the Catholic University of Chile

\begin{tabular}{|c|c|c|}
\hline Indications & Children $<18$ & Adults \\
\hline \multicolumn{3}{|l|}{ Malignant } \\
\hline Acute lymphoblastic leukemia & 44 & 34 \\
\hline Acute myelogenous leukemia & 23 & 35 \\
\hline Chronic Leukemia, myelodysplasia & 17 & 34 \\
\hline Lymphoma & 3 & 7 \\
\hline Other tumors & 4 & 1 \\
\hline Early disease & 66 & 84 \\
\hline Late disease & 24 & 24 \\
\hline \multicolumn{3}{|l|}{ Non malignant } \\
\hline Severe aplastic anemia & 13 & 10 \\
\hline Hystiocytosis & 4 & \\
\hline \multicolumn{3}{|l|}{ Congenital } \\
\hline Marrow failure syndromes & 9 & 1 \\
\hline Immunodeficiency & 11 & \\
\hline Hemoglobinopathy & & 1 \\
\hline Metabolic disorders & 8 & \\
\hline Sibling or other related donors & 76 & 91 \\
\hline Unrelated donors & 66 & 32 \\
\hline Cord blood & 60 & 26 \\
\hline Adult volunteer & 6 & 6 \\
\hline
\end{tabular}

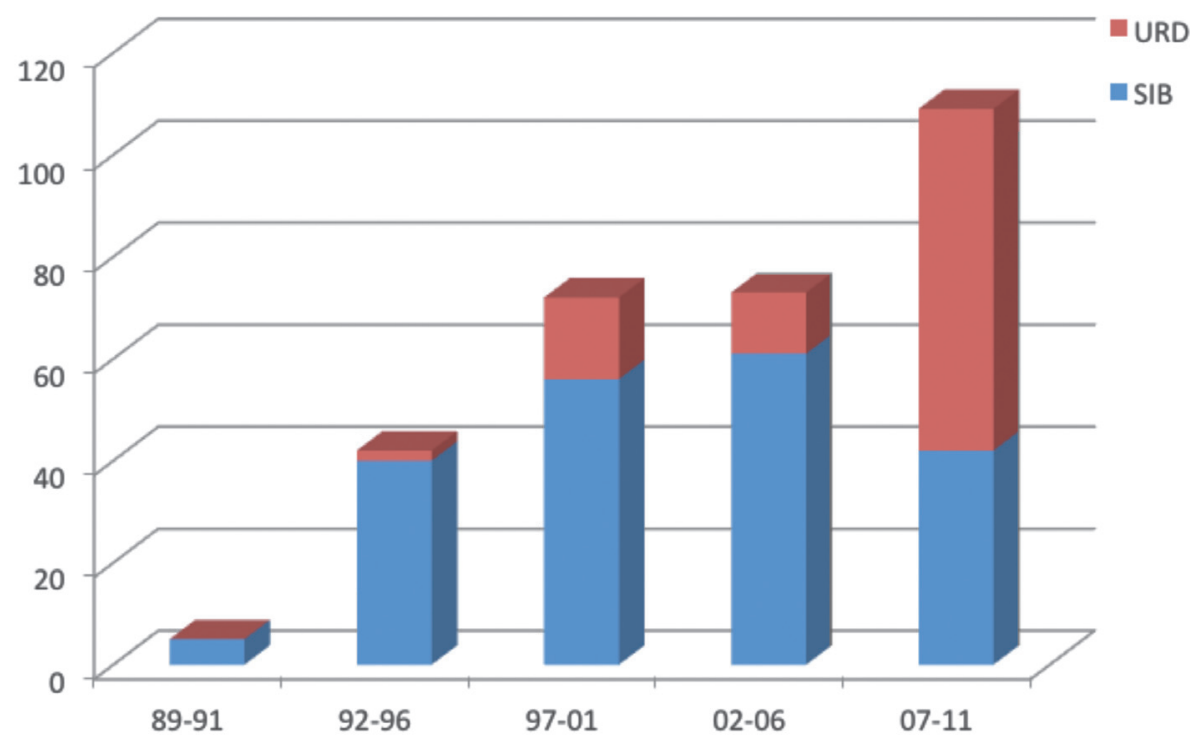

Figure 6. Evolution of donor types in the HSCT program at the Catholic University of Chile. Number of patients transplanted in different age periods. SIB: sibling or other related. URD: unrelated donor. 
factors emerged; donor source (sibling versus unrelated), the immune status of the patient (lymphopenic versus nonlymphopenic) and the presence of significant co-morbidities which were disease-related (active infections, severe iron overload and poor performance status). A worse prognosis was associated with the use of unrelated donors, with patients that had normal lymphocyte counts at transplantation and the presence of co-morbidities. When all three factors were scored together a powerful prognostic index was identified which allowed us to identify a group with a high risk of failure (5 year overall survival of $87 \%$ versus $26 \%$. p $<0.001$, Fig. 8 ).

\section{CONCLUSIONS}

HSC transplantation has developed into a mature field of medicine, reaching an ever growing number of patients worldwide thanks to improvements in transplantation techniques, center experience and donor availability. Our

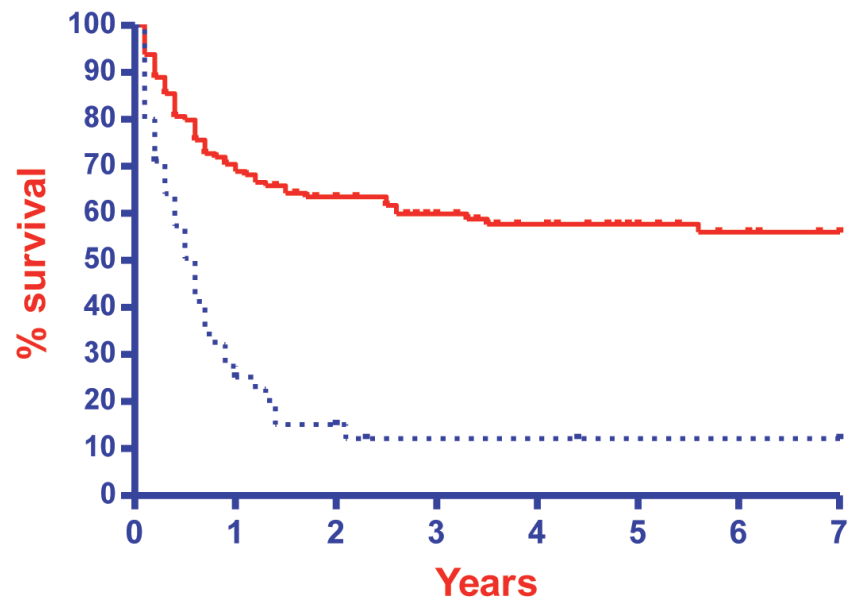

Figure 7. Allogenic HSCT results for patient with malignant diseases

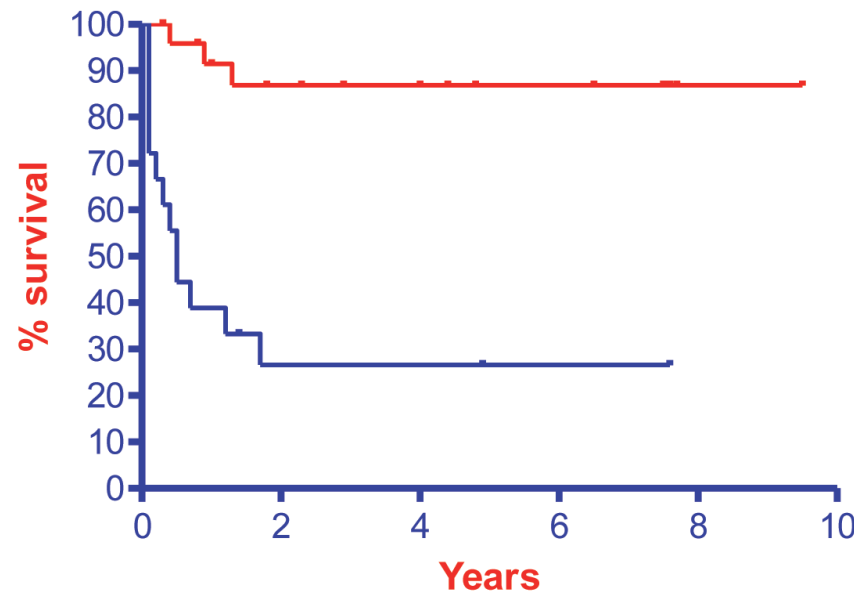

Figure 8. Allogeneic HSCT results in children with non malignant diseases. Prognostic score (PS): related donor: 0; unrelated donor: 1; lymphopenic patient: 0 ; nonlymphopenic: 1 ; without comorbidities:0; with comorbidities experience as well as that of many other centers has shown that patients with malignant diseases in need of transplantation should be evaluated and performed as soon as a donor is identified to avoid progression of their illness. Careful patient and donor selection will optimize results in patients with non-malignant disorders. Finally, continued improvements in the transplant process, in the understanding of the biology of hematopoietic stem cells and the ability to manipulate the immune system to develop a safer transplant procedure will help to benefit more patients without other realistic hope for a cure.

\section{REFERENCES}

BARKER JN, WEISDORF DJ, DEFOR TE, BLAZAR BR, MILLER JS, WAGNER JE (2003). Rapid and complete donor chimerism in adult recipients of unrelated donor umbilical cord blood transplantation after reduced-intensity conditioning. Blood 102:1915-1919.

BROXMEYER HE, DOUGLAS GW, HANGOC G, COOPER S, BARD J, ENGLISH D, ARNY M, THOMAS L, BOYSE EA (1989). Human umbilical cord blood as a potential source of transplantable hematopoietic stem/progenitor cells. Proc Natl Acad Sci USA 86:38283832.

BRUNSTEIN CG, GUTMAN JA, WEISDORF DJ, WOOLFREY AE, DEFOR TE, GOOLEY TA, VERNERIS MR, APPELBAUM FR, WAGNER JE, DELANEY C (2010). Allogeneic hematopoietic cell transplantation for hematologic malignancy: relative risks and benefits of double umbilical cord blood. Blood 116:4693-4699.

CALVI LM, ADAMS GB, WEIBRECHT KW, WEBER JM, OLSON DP, KNIGHT MC, MARTIN RP, SCHIPANI E, DIVIETI P, BRINGHURST FR, MILNER LA, KRONENBERG HM, SCADDEN DT (2003). Osteoblastic cells regulate the haematopoietic stem cell niche. Nature 425:841-846.

CHOI SW, LEVINE JE, FERRARA JL (2010). Pathogenesis and Managemen of Graft-versus-Host Disease. Immunol Allergy Clin N Am 30: 75-101.

CHUTE JP, SAINI AA, CHUTE DJ, WELLS MR, CLARK WB, HARLAN DM, PARK J, STULL MK, CIVIN C, DAVIS TA (2002). Ex vivo culture with human brain endothelial cells increases the SCID-repopulating capacity of adult human bone marrow. Blood 100: 4433-4439.

COPELAN EA (2006). Hematopoietic stem-cell transplantation. N Engl J Med 354:1813-1826.

DOAN PL, CHUTE JP (2012). The vascular niche: home for normal and malignant hematopoietic stem cells. Leukemia 26:54-62.

EMA H, NAKAUCHI H (2000). Expansion of hematopoietic stem cells in the developing liver of a mouse embryo. Blood 95:2284-2288.

FERRARA JL, LEVINE JE, REDDY P, HOLLER E (2009). Graft-versus-host disease. Lancet 373: 1550-61

FOEKEN LM, GREEN A, HURLEY CK, MARRY E, WIEGAND T, OUDSHOORN M (2010). Monitoring the international use of unrelated donors for transplantation: the WMDA annual reports. Bone Marrow Transplantation 45, 811-818.

GEKAS C, DIETERLEN-LIEVRE F, ORKIN SH, MIKKOLA HK (2005). The placenta is a niche for hematopoietic stem cells. Dev Cell 8:365-375.

GLUCKMAN E (2009). History of cord blood transplantation. Bone Marrow Transplant 44:621-626.

GLUCKMAN E, ROCHA V, BOYER-CHAMMARD A, LOCATELLI F, ARCESE W, PASQUINI R, ORTEGA J, SOUILLET G, FERREIRA E, LAPORTE JP, FERNÁNDEZ M, CHASTANG C (1997). Outcome of cord-blood transplantation from related and unrelated donors. Eurocord Transplant Group and the European Blood and Marrow Transplantation Group. N Engl J Med 337:373-381.

GUTMAN JA, LEISENRING W, APPELBAUM FR, WOOLFREY AE, DELANEY C (2009). Low relapse without excessive transplant-related mortality following myeloablative cord blood transplantation for acute leukemia in complete remission: a matched cohort analysis. Biol Blood Marrow Transplant 15:1122-1129.

GUTMAN JA, TURTLE CJ, MANLEY TJ, HEIMFELD S, BERNSTEIN ID, RIDDELL SR, DELANEY C (2010). Single-unit dominance after doubleunit umbilical cord blood transplantation coincides with a specific CD8+ T-cell response against the nonengrafted unit. Blood 115:757-765.

HOROWITZ ME, SULLIVAN KM (2006). Chronic graft-versus-host disease. Blood Reviews 20: 15-27.

HUBER TL, KOUSKOFF V, FEHLING HJ, PALIS J, KELLER G (2004). Haemangioblast commitment is initiated in the primitive streak of the mouse embryo. Nature 432:625-630. 
KASSIM AA, CHINRATANALAB W, FERRARA JLM, MINEISHI S (2005): Reduced-intensity allogeneic hematopoietic stem cell transplantation for acute leukemias: 'what is the best recipe?'. Bone Marrow Transplantation 36: 565-574

KIEL MJ, YILMAZ OH, IWASHITA T, TERHORST C, MORRISON SJ (2005). SLAM family receptors distinguish hematopoietic stem and progenitor cells and reveal endothelial niches for stem cells. Cell 121:1109-1121.

KNUDTZON S (1974). In vitro growth of granulocytic colonies from circulating cells in human cord blood. Blood 43:357-361.

KOPP HG, AVECILLA ST, HOOPER AT, SHMELKOV SV, RAMOS CA, ZHANG F, RAFII S (2005). Tie2 activation contributes to hemangiogenic regeneration after myelosuppression. Blood 106:505-513.

KRIVIT W (2004). Allogeneic stem cell transplantation for the treatment of lysosomal and peroxisomal metabolic diseases. Springer Semin Immun 26:119-132.

LAUGHLIN MJ, EAPEN M, RUBINSTEIN P, WAGNER JE, ZHANG MJ, CHAMPLIN RE, STEVENS C, BARKER LN, GALE RP, LAZARUS HM, MARKS DI, VAN ROOD JJ, SCARADAVOU A, HOPOWITZ MM (2004) Outcomes after transplantation of cord blood or bone marrow from unrelated donors in adults with leukemia. N Engl J Med 351:2265-2275.

LJUNGMAN P, BREGNI M, BRUNE M, CORNELISSEN J, DE WITTE T, DINI G, EINSELE H, GASPAR HB, GRATWOHL A, PASSWEG J, PETERS C, ROCHA V, SACCARDI R, SCHOUTEN H, SUREDA A, TICHELLI A, VELARDI A, NIEDERWIESER D; EUROPEAN GROUP FOR BLOOD AND MARROW TRANSPLANTATION. Allogeneic and autologous transplantation for haematological diseases, solid tumours and immune disorders: current practice in Europe 2009 (2010). Bone Marrow Transplantation 45, 219-234.

LO CELSO C, FLEMING HE, WU JW, ZHAO CX, MIAKE-LYE S, FUJISAKI J, CÔTE D, ROWE DW, LIN CP, SCADDEN DT (2009). Live-animal tracking of individual haematopoietic stem/progenitor cells in their niche. Nature 457:92-96.

LORENZ E, UPHOFF D, REID TR, SHELTON E (1951). Modification of irradiation injury in mice and guinea pigs by bone marrow injections. J Natl Cancer Inst 12:197-201.

LUCARELLI G, GALIMBERTI M, POLCHI P, ANGELUCCI E, BARONCIANI D, GIARDINI C, ANDREANI M, AGOSTINELLI F, ALBERTINI F, CLIFT RA (1993). Marrow Transplantation in patients with thalassemia responsive to iron chelation therapy. N Eng J Med 329: 840-4.

MANNICK JA, LOCHTE HL, ASHLEY CA, THOMAS ED, FERREBEE JW (1960). Autografts of bone marrow in dogs after lethal total-body radiation. Blood 15:255-266

MAURY S, BALÈRE-APPERT ML, CHIR Z, BOIRON JM, GALAMBRUN C, YAKOUBEN K, BORDIGONI P, MARIE-CARDINE A, MILPIED N, KANOLD J, MAILLARD N, SOCIÉ G; FRENCH SOCIETY OF BONE MARROW TRANSPLANTATION AND CELLULAR THERAPY (SFGMTC) (2007). Unrelated stem cell transplantation for severe acquired aplastic anemia: improved outcome in the era of high-resolution HLA matching between donor and recipient. Haematologica 92:589-596.

MUÑOZ VILLA A, DÍAZ DE HEREDIA C, DÍAZ GONZÁLEZ MA, BADELL SERRA I, MARTÍNEZ RUBIO A, GONZÁLEZ VALENTÍN MA, DAS CARPIO MA, GÓMEZ PÉREZ P, BUREO DACAL E, OLIVÉ OLIVERAS T, PÉREZ HURTADO JM, MALDONADO REGALADO MS (2008). Severe acquired aplastic anemia: historical outcome of patients treated by allogeneic bone marrow transplantation from matched sibling donors. A study by the Spanish Group for Bone Marrow Transplantation in Children (GETMON) An Pediatr (Barc) 69:5-9.

PASQUINI MC, WANG Z (2011). Current use and outcome of hematopoietic stem cell transplantation: CIBMTR Summary Slides 2011. Available at: http: / / www.cibmtr.org

PASSWEG JR, BALDOMERO H, GRATWOHL A (2012). The EBMT activity survey: 1990-2010. Bone Marrow Transplantation 47, 906-923.

PETERSDORF E (2008). Optimal HLA matching in hematopoietic cell transplantation. Current Opinion in Immunology 20: 588-593.
PRASAD VK, MENDIZÁBAL A, PARIKH SH, SZABOLCS P, DRISCOLL TA, PAGE K, LAKSHMINARAYANAN S, ALLISON J, WOOD S, SEMMEL D, ESCOLAR ML, MARTIN PL, CARTER S, KURTZBERG J (2008). Unrelated donor umbilical cord blood transplantation for inherited metabolic disorders in 159 pediatric patients from a single center: influence of cellular composition of the graft on transplantation outcomes. Blood 112: 2979-2989.

RAMÍREZ P, WAGNER JE, DEFOR TE, BLAZAR BR, VERNERIS MR, MILLER JS, MCKENNA DH, WEISDORF DJ, MCGLAVE PB, BRUNSTEIN CG (2012). Factors predicting single-unit predominance after double umbilical cord blood transplantation. Bone Marrow Transplant 47:799-803.

RETTIG MP, ANSSTAS G, DIPERSIO JF (2012). Mobilization of hematopoietic stem and progenitor cells using inhibitors of CXCR4 and VLA-4. Leukemia 26:34-53.

ROCHA V, LABOPIN M, SANZ G, ARCESE W, SCHWERDTFEGER R, BOSI A, JACOBSEN N, RUUTU T, DE LIMA M, FINKE J, FRASSONI F, GLUCKMAN E; ACUTE LEUKEMIA WRKING PARTY OF EUROPEAN BLOOD AND MARROW TRANSPLANT GROUP; EUROCORDNETCORD REGISTRY (2004). Transplants of umbilical-cord blood or bone marrow from unrelated donors in adults with acute leukemia. N Engl J Med 351:2276-2285.

RUBINSTEIN P, CARRIER C, SCARADAVOU A, KURTZBERG J, ADAMSON J, MIGLIACCIO AR, BERKOWITZ RL, CABBAD M, DOBRILA NL, TAYLOR PE, ROSENFIELD RE, STEVENS CE (1998). Outcomes among 562 recipients of placental-blood transplants from unrelated donors. N Engl J Med 339:1565-1577.

SANTOS GW, OWENS AH (1969). Allogeneic marrow transplants in cyclophosphamide treated mice. Transplant Proc 1:44-46.

SCHOFIELD R (1978). The relationship between the spleen colony-forming cell and the haemopoietic stem cell. Blood Cells 4:7-25.

SHENOY S (2011). Hematopoietic Stem Cell Transplantation for Sickle Cell Disease: Current Practice and Emerging Trends. Hematology 2011: 273279; doi:10.1182/ asheducation-2011.1.273

SLATTER MA, CANT AJ (2011). Hematopoietic stem cell transplantation for primary immunodeficiency diseases. Ann N Y Acad Sci 1238 122-131.

STOREK I, DAWSON MA, STORER B, STEVENS-AYERS T, MALONEY DG, MARR KA, WITHERSPOON RP, BENSINGER W, FLOWERS ME, MARTIN P, STORB R, APPELBAUM FR, BOECKH M. (2001) Immune reconstitution after allogeneic marrow transplantation compared with blood stem cell transplantation. Blood; 97(11):3380-9.

THOMAS ED, STORB R, CLIFT RA, FEFER FA, JOHNSON FL, NEIMAN PE, LERNER KG, GLUCKSBERG H, BUCKNER CD (1975). Bone-Marrow Transplantation. N Engl J Med 292:832-843.

TILL JE, MCCULLOCH EA (1961). A direct measurement of the radiation sensitivity of normal mouse bone marrow cells. Radiat Res 14:213-222.

TOMBLYN M, CHILLER T, EINSELE H, GRESS R, SEPKOWITZ K, STOREK J, WINGARD JR, YOUNG JA, BOECKH MJ. (2009). Guidelines for preventing infectious complications among hematopoietic cell transplantation recipients: a global perspective. Biol Blood Marrow Transplant; 15(10):1143-238.

VLACHOS A, MUIR E (2010). How I treat Diamond-Blackfan anemia. Blood 116: 3715-3723.

WACHOWIAK J, LABOPIN M, MIANO M, CHYBICKA A, STARY J, STERBA J, MASSZI T, LABAR B, MASCHAN A, KOWALCZYK JR, LANGE A, HOLOWIECKI J, KALMAN N, AFANASSIEV BV, DINI G; EBMT PAEDIATRIC WORKING PARTY (2008). Haematopoietic stem cell transplantation in children in eastern European countries 1985-2004: development, recent activity and role of the EBMT/ESH Outreach Programme. Bone Marrow Transplantation 41, S112-S117.

YIN T, LI L (2006). The stem cell niches in bone. J Clin Invest 116:1195-1201.

ZHANG CC, KABA M, IIZUKA S, HUYNH H, LODISH HF (2008). Angiopoietin-like 5 and IGFBP2 stimulate ex vivo expansion of human cord blood hematopoietic stem cells as assayed by NOD/SCID transplantation. Blood 111:3415-3423. 